National School of Veterinary Medecin of

Sidi Thabet
International Center for Agricultural

Research in the Dry Areas

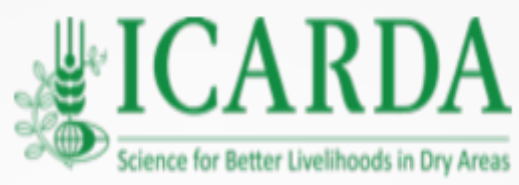

National Agronomic Institute of Tunisia

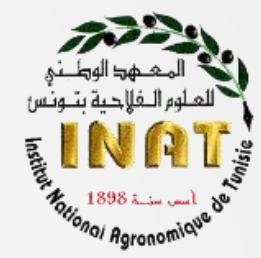

First detection and molecular identification of Neospora caninum from naturally infected cattle and sheep in North Africa

\author{
Yosra Amdouni
}

amdouniyosra,ay@gmail,com 


\title{
Published
}

\section{First detection and molecular identification of Neospora caninum from naturally infected cattle and sheep in North Africa}

\author{
Y. Amdouni ${ }^{1}\left(\mathbb{D} \mid\right.$ M. R. Rjeibi ${ }^{1}$ (D) S. Awadi ${ }^{2}$ | M. Rekik ${ }^{3}$ | M. Gharbi ${ }^{1}(\mathbb{C}$
}

\footnotetext{
${ }^{1}$ Laboratoire de Parasitologie, Institution de la Recherche et de l'Enseignement Supérieur Agricoles, École Nationale de Médecine Vétérinaire de Sidi Thabet, Univ. Manouba, Ariana,Tunisia

${ }^{2}$ Regional Slaughterhouse of Béja, Béja, Tunisia

${ }^{3}$ International Center for Agricultural Research in the Dry Areas (ICARDA),

Amman, Jordan
}

\section{Summary}

Neosporosis, caused by the protozoan Neospora caninum, is a major cause of reproductive failure in ruminants causing enormous economic losses. The objective of this study was to estimate the infection rate and molecular identification of $N$. caninum in Tunisian cattle and sheep. A total number of 348 meat samples were collected from 150 cows and 198 ewes slaughtered in the regional slaughterhouse of Béja (North-west Tunisia) and tested for the presence of N. caninum ITS1 gene using 


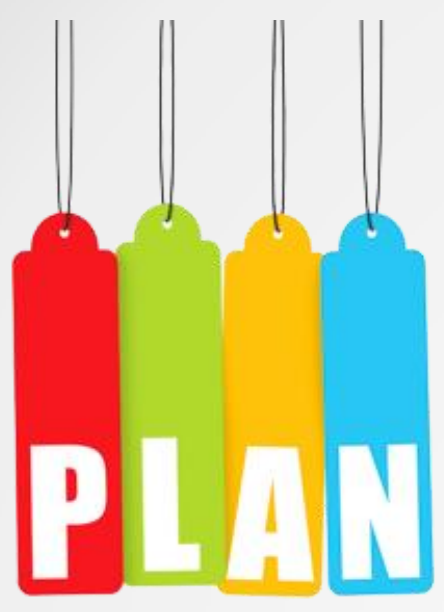

Background

Objectifs

Methodology

Résultats \& Discussion

Conclusion 


\section{Background}

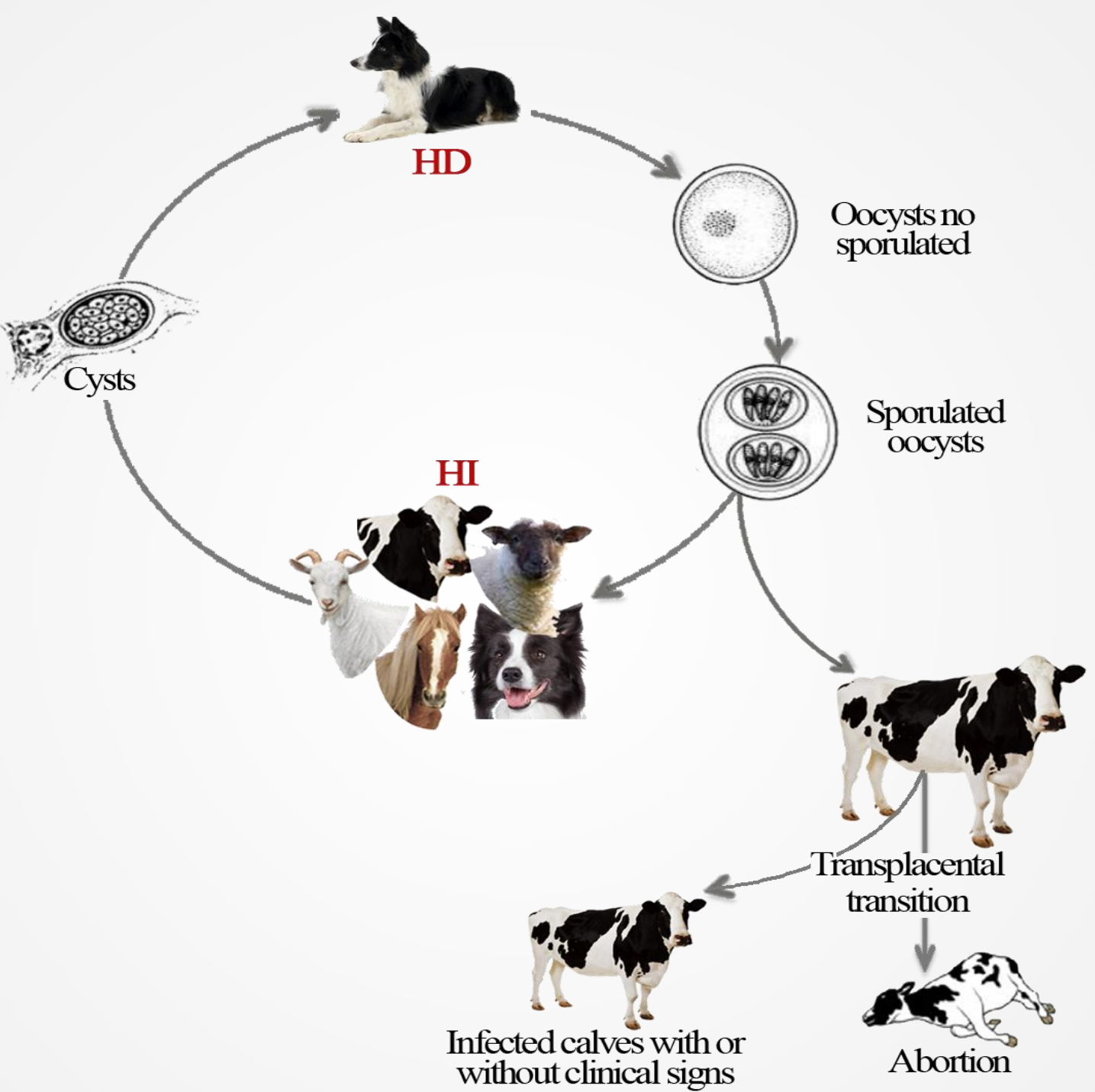

HI : Intermediate host 


\section{Background Economic losses (Dubey et al., 2007)}

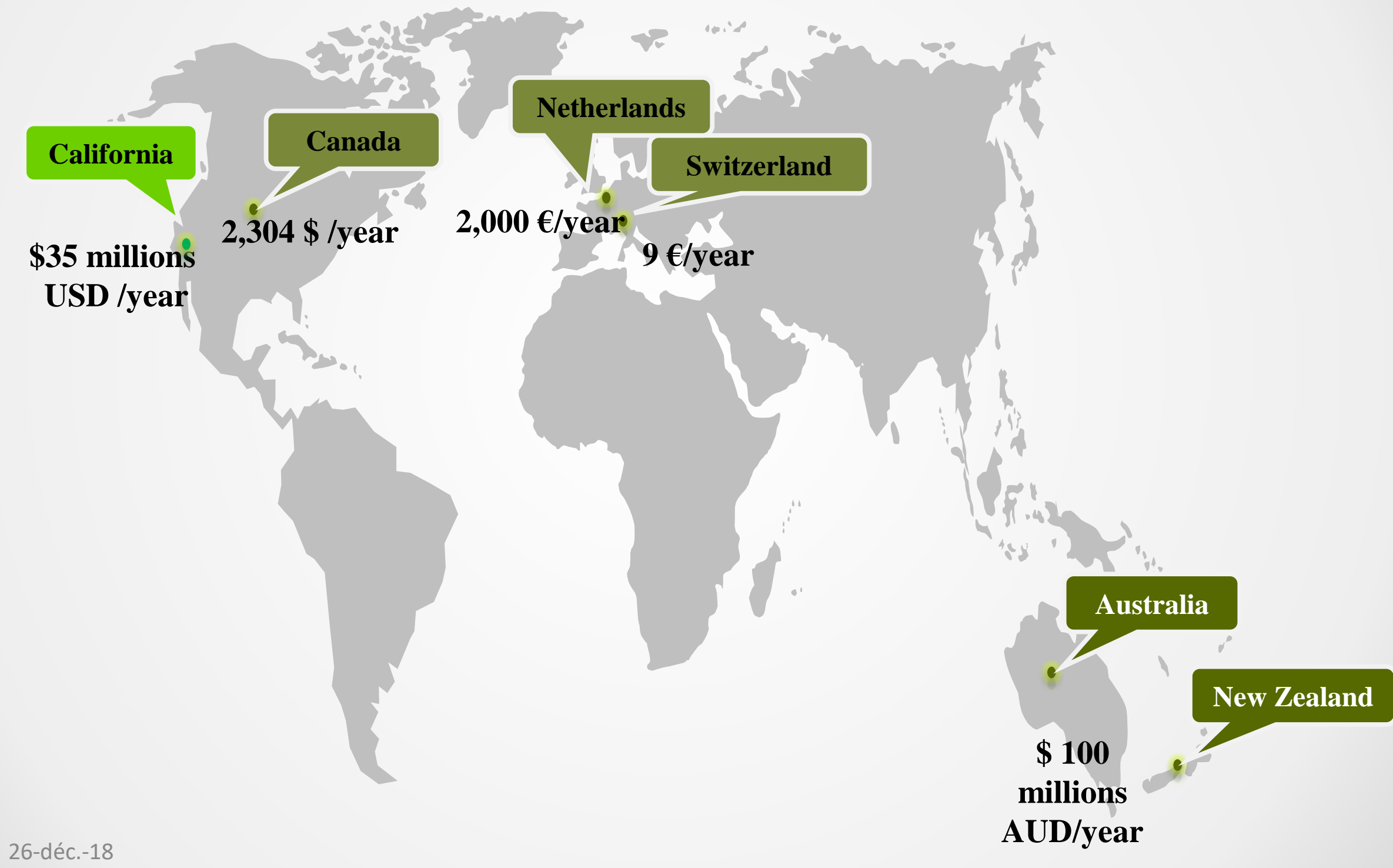




\section{Objectifs}

\section{1}

Estimate the infection rate of

Neospora caninum in Tunisian cattle and sheep

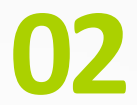

Estimate the risk factors associated with Nospora caninum infection

\section{3}

Phylogenetic analysis of Neospora caninum in Tunisian cattle and sheep 


\section{Methodology}

Collect of 150 and 198 meat samples respectively from cattle and sheep

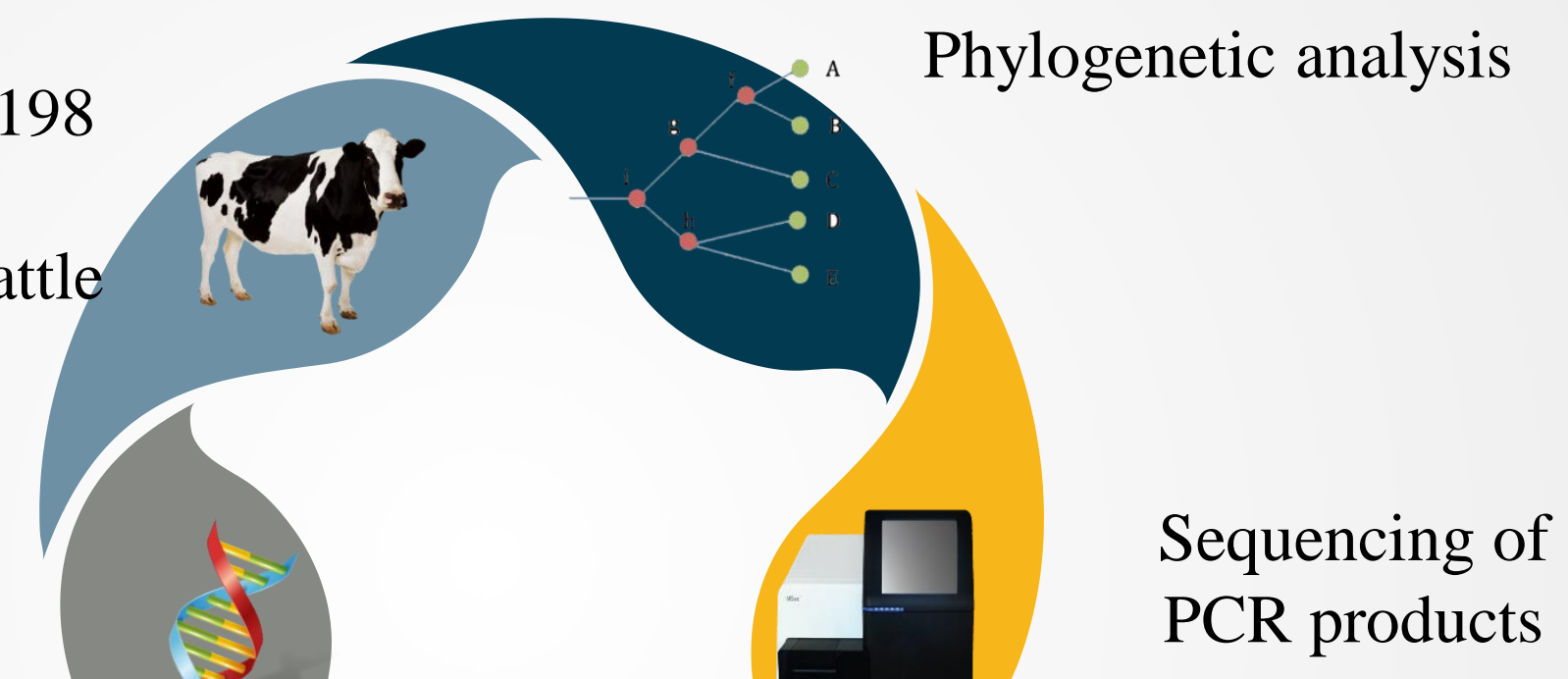

DNA extraction using gnomique (kit Wizard Genomics (Promega, Madisson)

Universal PCRs \& spécific PCRs (détection of $N$. 


\section{Résultats \& discussion}

- Molecular prevalence
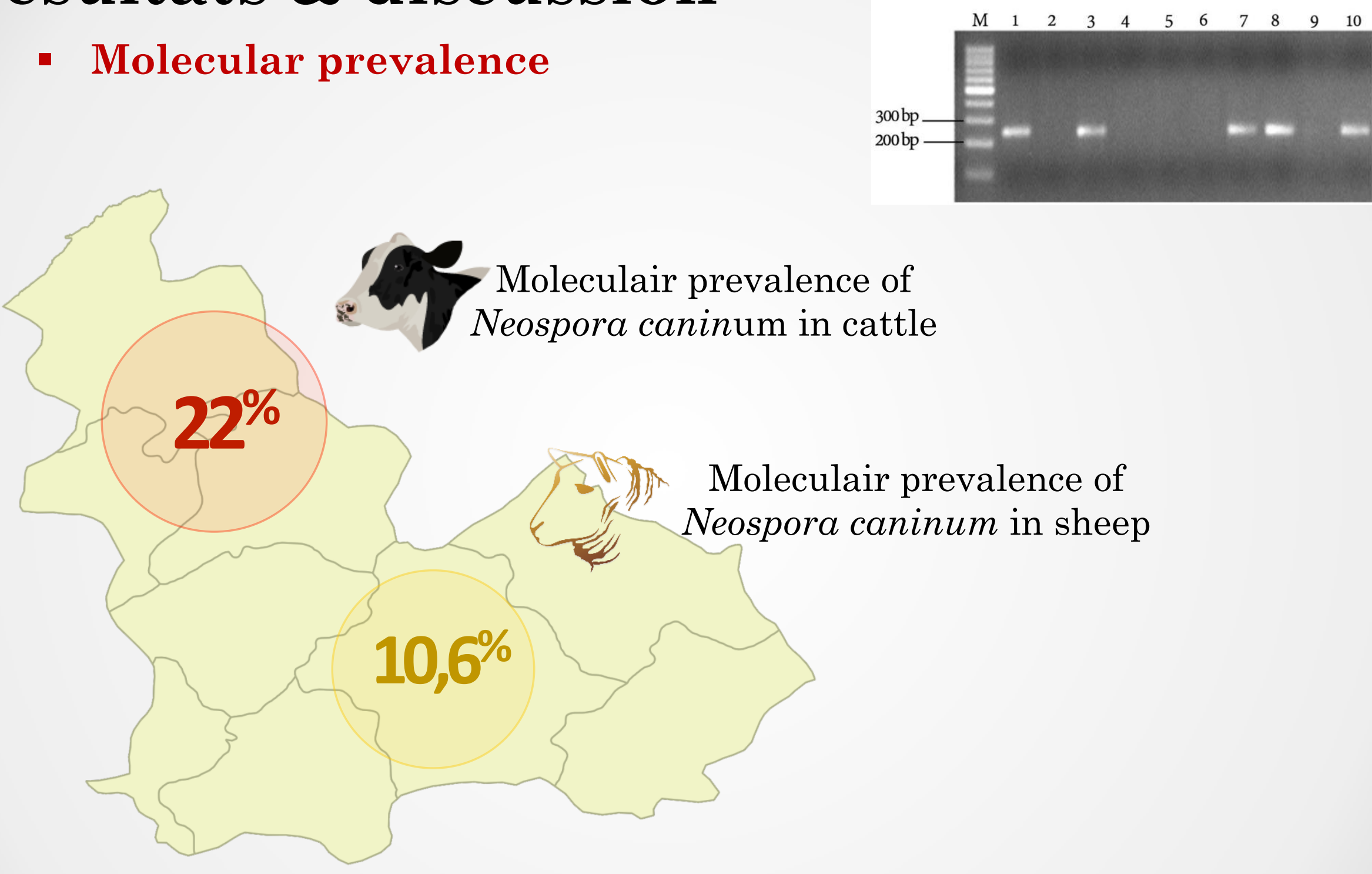

High susceptibility of cattle to $N$. caninum infection (Pan et al., 2004). 


\section{Résultats \& discussion}

- Risk factors : Localities

N. Caninum in sheep

Close contact with oocysts shed by dogs very often used as shepherd dogs,

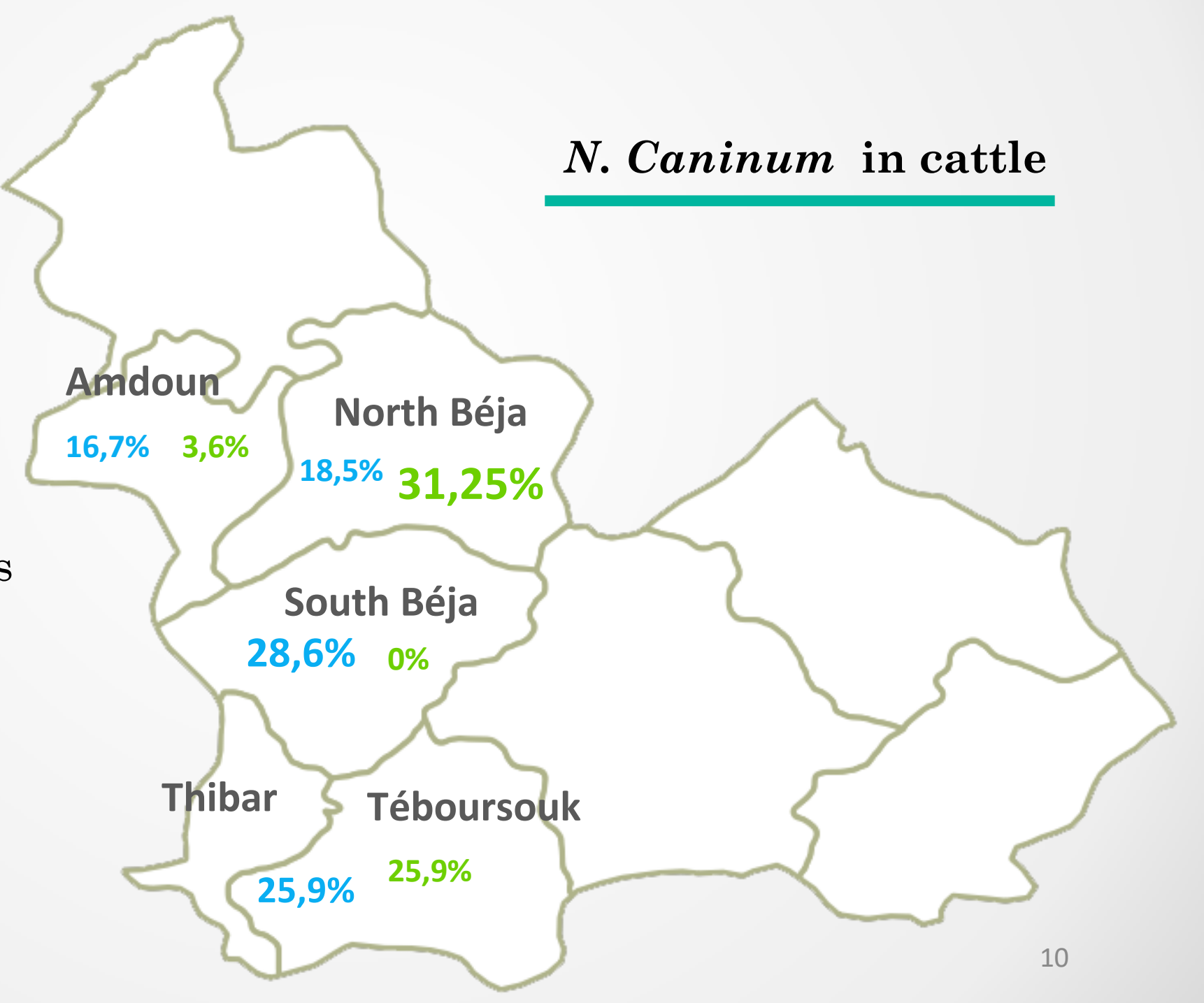




\section{Résultats \& discussion}

- Risk factors : Age

\begin{tabular}{llll}
\hline Species & Age group & $\begin{array}{l}\text { Positive/examined } \\
\text { (\%SE) }\end{array}$ & P value \\
\hline Sheep & $<1$ & $7 / 126(5.6 \pm 4)$ & $0.002^{*}$ \\
& $\geq 1$ & $14 / 72(\mathbf{1 9 . 4} \pm 9.1)$ & \\
Cattle & $<2$ & $6 / 54(\mathbf{1 1 . 1} \pm 8.4)$ & $0.05^{*}$ \\
& {$[2-8[$} & $19 / 66(28.8 \pm 10.9)$ & \\
& $\geq 8$ & $8 / 30(26.7 \pm 15.8)$ & \\
\hline
\end{tabular}

Table: Association between N. caninum infection prevalence and age group

This association with age indicates the presence of an horizontal transmission by ingestion of sporulated oocysts (Figliuolo et al., 2004).

This transmission pathway is indicating the presence of a high abortion risk associated with $N$. caninum infection in naïve ruminants. 


\section{Résultats \& discussion}

- Risk factors : Breed

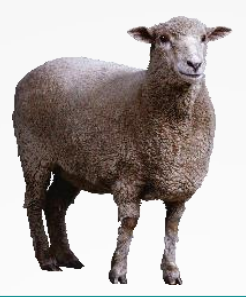

Compared to Barbarine animals (6.8 4.5\%), the infection prevalence by $N$. caninum was higher in Noire de Thibar animals (31.7 $14.2 \% ; \mathrm{p}<.001)$.

These results may be due to a higher genetic resistance of local breeds to $N$. caninum in comparison with other breeds and this may be a novel area of research. 


\section{Résultats \& discussion}

- Risk factors : Breed

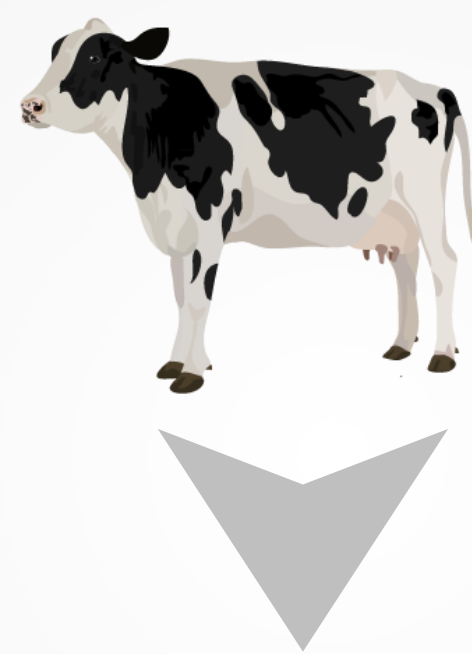

No differences were depicted in the molecular prevalence of $N$. caninum according to cattle breeds ( $p>.05)$. 


\section{Résultats \& discussion}

- Phylogenetic analysis

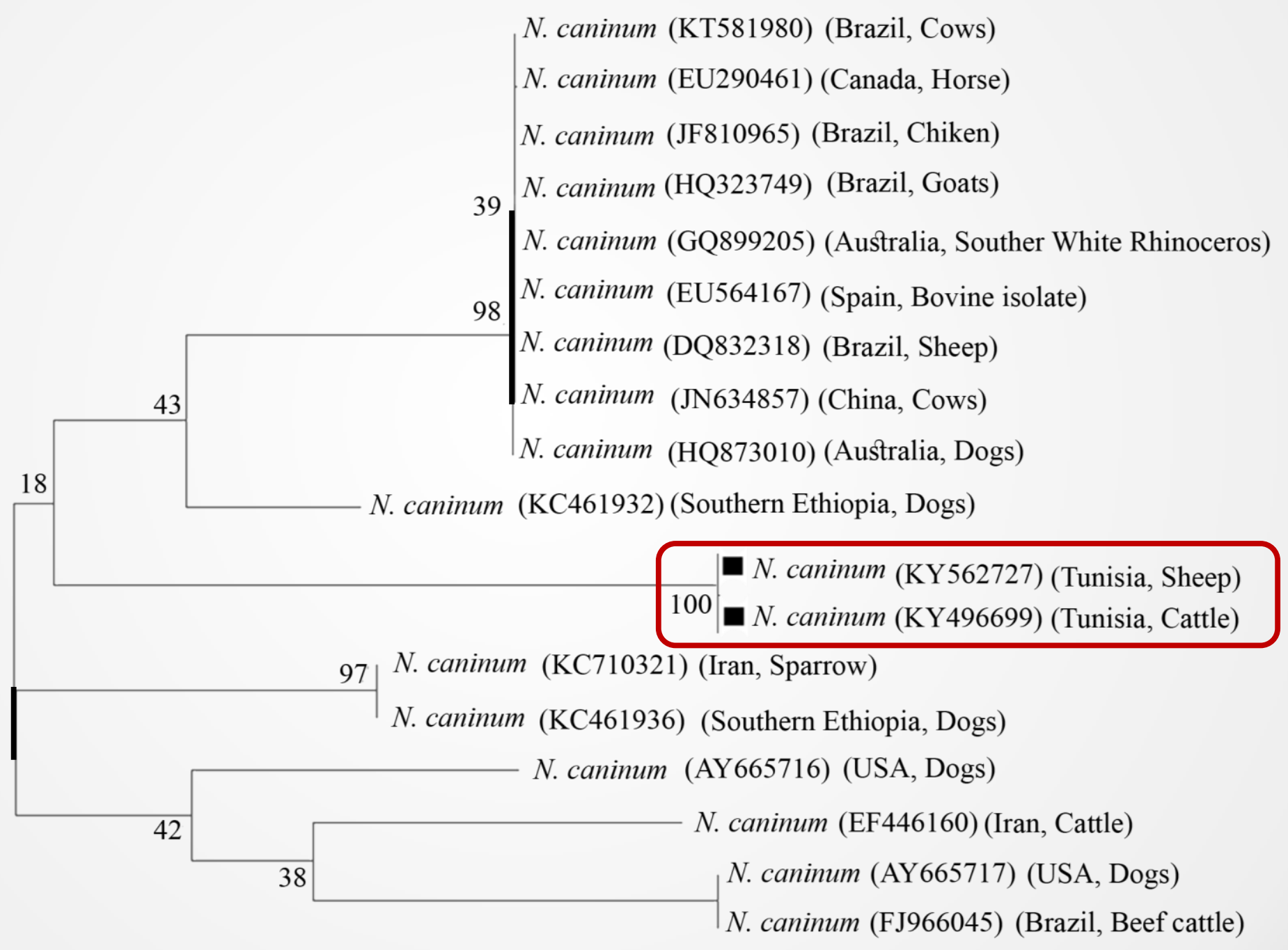




\section{Résultats \& discussion}

- Phylogenetic analysis

Based on the alignment of the two sequences of $N$. caninum from each host species (cattle and sheep), the phylogenetic tree showed two clusters:

- In the first cluster, sequences were close with sequences from Latin America (Brazil), Southern Europe (Spain) and Asia (Australia and China).

- The second cluster included sequences from North America (USA), Africa (Southern Ethiopia) and Asia (Iran). 


\section{Conclusion}

+++ Studies in other regional slaughterhouses are necessary to estimate the geographical prevalence of $N$ caninum infection in Tunisian cattle and sheep and to better explore the role of this parasite in both cattle and sheep abortions.

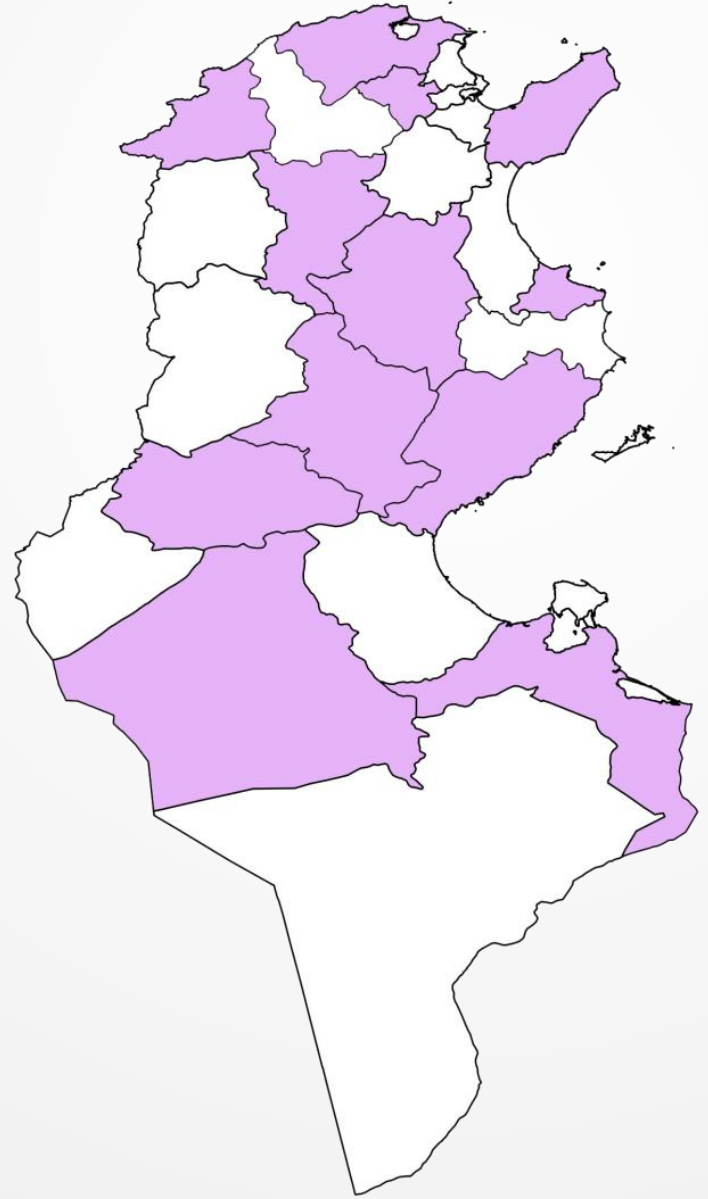




\section{Acknowledgment}

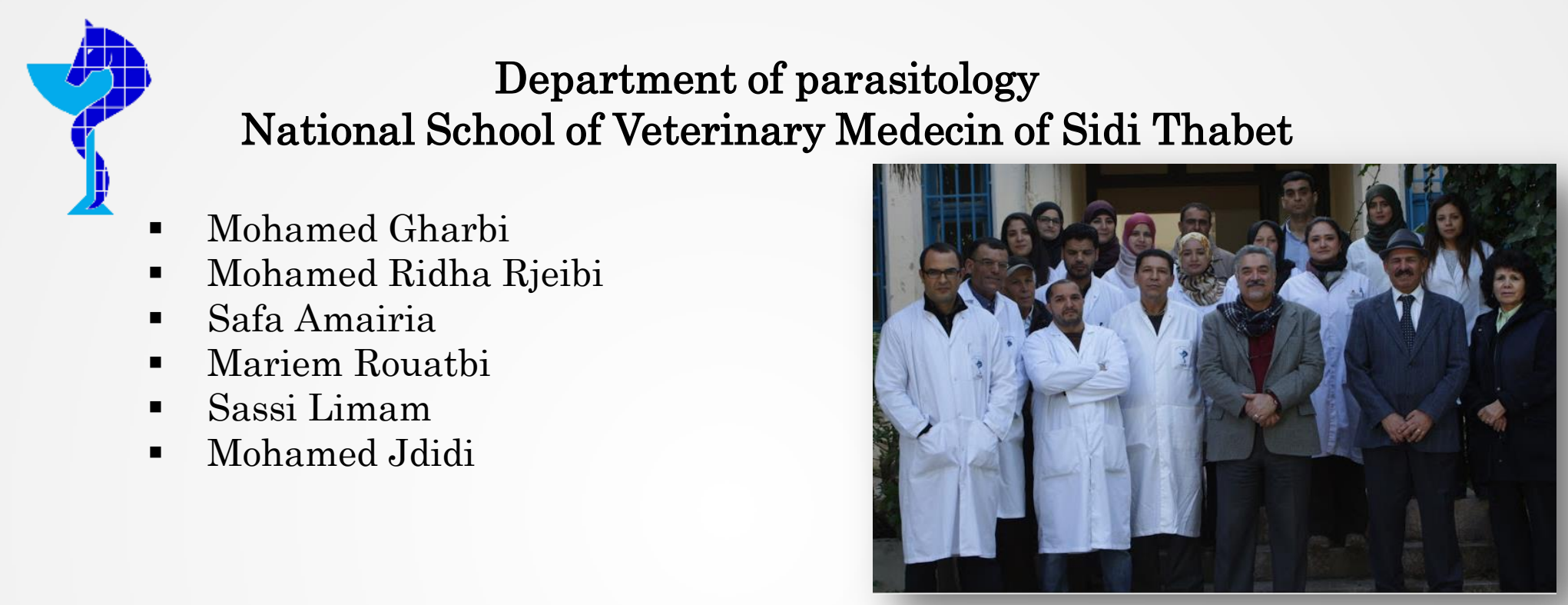

ICARDA International Center for Agricultural

Research in the Dry Areas

- Mourad Rekik

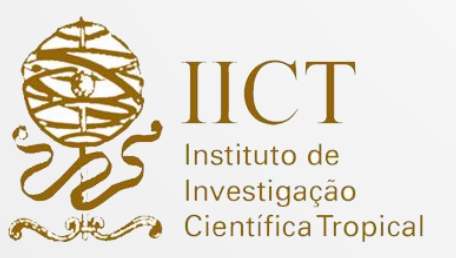

Institute of Tropical Scientific Research, Portugal

- Alexandre Leitão 


\section{Thank you}

